\title{
The impact of ISO 9001 Quality Management on organizational learning and innovation: Proposal for a conceptual framework
}

\author{
C.E.Mokhlis ${ }^{1 *}$, A. Elmortada ${ }^{2}$, M. Sbihi ${ }^{3}$, K. Mokhlis ${ }^{4}$ \\ 1, Laboratory of Scientific Engineering of Organizations, Ecole Nationale de Commerce et de Gestion, \\ Hassan II University, Morroco. \\ ${ }^{2,4}$ Laboratory Process Signaux Système Industriel et Informatique \\ Cadi Ayyad University \\ ${ }^{3}$ Institut Supérieur de Commerce et d'Administration des Entreprises, Casablanca, Morroco
}

\section{Article Info}

Received Jan 4, 2019

\section{Keyword:}

Quality Management

ISO 9001 Certification

Knowledge Management

Organizational Learning

Sustainable competitive

advantage

Corresponding Author:

Chams Eddoha MOKHLIS

Departement of management,

Ecole Nationale de Commerce et de Gestion,

Hassan II University

2725 Route des Chaux et Ciments, Casablanca 20250, Morroco.

Email: chams.mokhlis@gmail.com

\begin{abstract}
The integration of the learning perspective and knowledge management has led us in this research to develop a framework for analyzing the influence of a management system of quality on organizational learning and innovation within certified companies. By conceptualizing a framework of analysis including contextual and methodological elements, we theoretically develop how a management system of quality such as ISO 9001 can produce different types of learning and knowledge and how the advantage of quality can become more sustainable.
\end{abstract}

\section{Introduction}

The increasing intensity of environmental complexity and the dynamism of competition in different sectors of activity are constantly generating changes in the business strategy since the end of the eighties. Indeed, the development of companies is no longer based on the static perspectives of evolution of the market / product pair based on the classic industrial model, but on the development linked to the evolution of its knowledge and its own competences [1].

From the point of view of the Resource Based View, the most decisive resources for achieving increased performance are no longer tangible traditional assets, but immaterial dynamic abilities [2].

Moreover, in their pioneering work, Benner and Tushman emphasized on the idea of balancing the firm's dynamic capabilities between exploitation and exploration as suggested by the theoreticians of strategy and organization [3]. According to this author, the firm's competitive capability can dwell on its ability to both integrate and develop its current competences while simultaneously developing fundamentally new capabilities.

In light of this argument, we argue that the knowledge management activity should mingle with experience enrichment and the design of routines and the establishment of clear procedures and controls to exploit this knowledge. 
The risk is always there, that this balance between exploration and exploitation becomes asymmetrical to the latter and that the routines encourage automation of operations and rigidity. Established knowledge becomes a source of comforting certainty that reduces the possibility of seizing future opportunities [4].

Since knowledge management may seem like a wavering practice between creativity and the exploitation of acquired knowledge, researchers need more insight into how innovation is born from models that are constantly negotiated and socially integrated with activities of the organization. It seemed appropriate to conduct a research project in this area. Our research tends to study learning through the concepts of exploration and exploitation [3] and to probe the creation of both tacit and explicit knowledge [5, 6].

More specifically, we studied the influence of the use of an ISO 9001 quality management system on learning and knowledge creation. Although this quality system is not openly declared as a knowledge management tool, some researchers suggest that it provides a favorable context for the development of knowledge [7, 8].

On the other hand; others look at these systems as a means of stiffening the organization by strengthening the prescription of work and limiting the autonomy of staff [9].

In addition to their controversial results, most of the studies that have examined the impact of quality management on learning, consider the quality system as a homogeneous set of practices and do not take into account the specificities of its components. However, some authors [10] suggest that quality systems should be split into two categories: technical components (statistical control of processes, the use of benchmarking or the implementation of flexible processes) and social or contextual components (leadership, staff involvement, customer orientation, training and development of staff skills, teamwork, communication, shared vision). Overall, despite the presence of work on technical and social quality, there is a lack of understanding of how these components can influence learning and knowledge creation. Our research attempts to fill these gaps by proposing a basic elements framework of an ISO 9001 quality system and examines how learning and knowledge creation and innovation can be facilitated.

This leads us to state our main research question:

- "How does the use of Quality management system (QMS) ISO 9001 influence learning and the capacity for innovation"?

Other questions emerge:

- How can each of the two components of the QMS (technical and contextual) influence learning and knowledge creation?

- How can each of the two components of the QMS (technical and contextual) influence the ability to innovate?

- How can the articulation between these two components influence learning, knowledge creation and innovation?

- How can the articulation between these two components contribute to the sustainability of the competitive advantage?

\section{Theoretical framework and main concepts}

Our research is mainly in the literature on the links between quality management and organizational learning. We can cite, among other things, the qualitative research carried out in this field by [11].These authors demonstrated that specific knowledge management tools have complementary links with the quality procedures. Quality approaches will organize the circulation of this knowledge, thanks to the formalization process and standardization, while knowledge management will manage the creation of them.

Similarly, Lambert and Ouédraogo [7] studied the impact of ISO 9001 management systems on some aspects of organizational learning and how these affect the performance of processes. By conducting a statistical study, they showed that operational learning positively affects performance in the short term while long-term performance requires both operational and conceptual learning.

We can also mention the study conducted by Lambert and Ouedraogo [8]. These authors analyzed two extreme cases of implementation of the ISO 9001: 2000 and show that the performers' interpretation has important consequences for organizational learning. In the first case, they observed a restricted learning following a prescribed implementation of the QMS as well as a strict interpretation of the standard. In the second case, a richer learning emerged during the implementation of the routines but based on a "loose" interpretation of the ISO 9001 standard.

While some researchers have found a positive link between quality management and organizational learning, other authors for example: (Boiral [12], Igalens [13] questioned the relevance of these management systems 
because they adopt a mechanistic view of the organization and an instrumental approach to management that may reduce the staff's sense of autonomy and limit learning.

Thus, despite the presence of a number of interesting works on the link between quality management and learning, their findings remain contradictory. Moreover, as we have already pointed out, most of these studies consider the quality system as a homogeneous set of practices and do not take into account the specificities of its components. Although some researchers have studied quality approaches both socially and technically, these studies have considered quality management as essentially technical, focusing on the use of scientific techniques and methods [14]. Others have found that, despite the basic technical content of quality, social processes form the way quality is practiced within organizations $[12,10]$.

In addition, research on organizational knowledge management can be classified into two streams "methodological and contextual". On the one hand, the "Methodological" perspective emphasizes on the support of a formal method of problem solving that promotes rationality and brightens decision-making by enabling an organization to systematically collect, generate and apply knowledge [15].

On the other hand, the "contextual" perspective emphasizes on the importance of a supportive social environment of knowledge creation [5], Nonaka and takeuchi [16]. These two perspectives represent the dual emphasis of quality practices: "social" and "technical". In our research, we have integrated technical and contextual aspects that reflect these two perspectives of organizational knowledge management.

\section{Analysis framework}

Based on the trails raised by the literature, we have designed a quality system that includes contextual elements (soft aspects of quality) and technical elements (hard aspects of quality). This system allowed us to conceptualize a framework for analyzing how a QMS can influence learning, knowledge and innovation. We will develop the contextual elements and the technical elements and then we will examine how these elements can complement each other to maintain the sustainability of the competitive advantage.

\subsection{Technical elements}

Effective implementation of ISO 9001 requires the use of structured methods and techniques to foster learning and knowledge creation. There are three elements: process management, the use of a set of analysis tools, and the use of common metrics. These elements do not work independently, but they overlap with each other.

\section{- Adoption of process management}

The ISO 9001 standard [17] emphasizes on the importance of process management. It urges the use of the Deming Cycle, or the PDCA cycle (plan, Do, check, Act) for the improvement of Process Incremental thanks to the learning experience.

The implementation of a process management system is essentially based on the definition of a process mapping, the formalization of a documentary system, the establishment of an evaluation system and reviews to measure processes, identify areas for progress and capitalize on good practices.

\section{- Using a set of analysis tools}

Quality tools can include a wide variety of statistical methods and charts for work activity planning, data collection, results analysis, monitoring progress and problem solving. In addition, the ISO 9001 standard requires the analysis of data in a factual way. This requires the implementation of tools such as: indicators and dashboards, teamwork, reengineering, benchmarking, brainstorming, step-by-step problem solving methods and the use of ICT technologies, help to meet this need and make decision-making effective. This data analysis is likely to promote learning through the identification and resolution of complicated problems.

\section{- The use of common metrics parameters}

Previous researches have shown that a good integration of TQM in the company's daily activities requires "a language compatible with the existing activity of the organization that would help them to understand and integrate TQM techniques" [10] Coherent and comprehensive measures can be used as a common "language" and a reference to which all the company's projects are evaluated [18]. Similarly, common metrics help coordinate knowledge creation efforts by integrating and adapting problem solving through the organization. 


\subsection{Elements of the organizational context}

Although the technical elements are important, they are not sufficient to guarantee the improvement of quality and to promote learning. Organizations manage better their knowledge when forming a social environment that promotes creativity for its members. The management of knowledge creation is actually based on the ability to build "enabling context" [19]. Nonaka and takeuchi [16] describe this context as "a support process that upholds the knowledge creation ". We will retain four contextual elements: leadership support, client and partnership orientation, availability of sufficient resources and the involvement of human resources.

\section{- Leadership support}

According to the ISO standard (ISO 9001: 2015), the Management must establish the purpose and orientations of the organization through a consistent quality policy with the company's strategy. The implementation of this principle implies that Management is required to develop the mission, vision, values of the organization, to become involved in improvement activities, to encourage and stimulate learning activities, and innovation through the establishment of an "enabling" environment. Some authors believe that organizational cultures that tolerate error and encourage initiative are more learners. Other authors such as (Senge, 1999) have argued that leadership reinforces the shared vision in a learning organization by creating "the need to learn and the collective will to learn" [16].

\section{- Customer orientation and partnership}

The client and, in a broader sense, the "stakeholders", are at the center of the organization's operations. In the context of beneficial relationships with suppliers and feedback from customers, the company will benefit from the knowledge of its environment. The standard (ISO 9001: 2015) also states that the organization must communicate with customers about product information, as well as about feedback, including claims. In general, mutual beneficial relationships can extend to all partners, for example community, universities and other research institutions are an important means of integrating external knowledge, which enriches the knowledge base of the company.

\section{- Sufficient resources}

Accessibility of resources has been found to be positively related to learning and innovation [21]. It influences mutual cooperation between employees, which leads to collective learning. Other authors [22] have stated that sufficient resources, such as facilities, equipment, information and funds, contribute to the scientific creativity of R \& D.

\section{- Involvement of human resources}

The ISO 9001 and TQM quality standards fully cover this aspect and underline the importance of training, employees' autonomy and their participation. Moreover, the self-determination theory directly links Human Relations with organizational learning. Once the organization guarantees autonomy and motivation to individuals, they implement their potential tendency to explore and learn [23].

\section{Results: Integrated framework}

To examine the impact of the Quality Management System on learning, knowledge and innovation, we designed a quality system that includes contextual and methodological elements. Our central hypothesis is that the contextual elements are related to exploratory learning, tacit knowledge and radical innovations, while the technical elements are related to exploitative learning, explicit knowledge and incremental innovations. We then showed that a "loose" articulation between contextual and technical elements facilitates the balance between operational learning and exploratory learning, and generates diverse knowledge and innovations. Finally, we have argued that the balance between exploratory and exploitative learning, maintaining heterogeneous knowledge, and developing a dual innovation capability can lead to maintaining the sustainability of the competitive advantage.

These relationships are shown in Figure (1).The following sections will present the details of our development. 
Figurel: The impact of the QMS on learning, knowledge and innovation

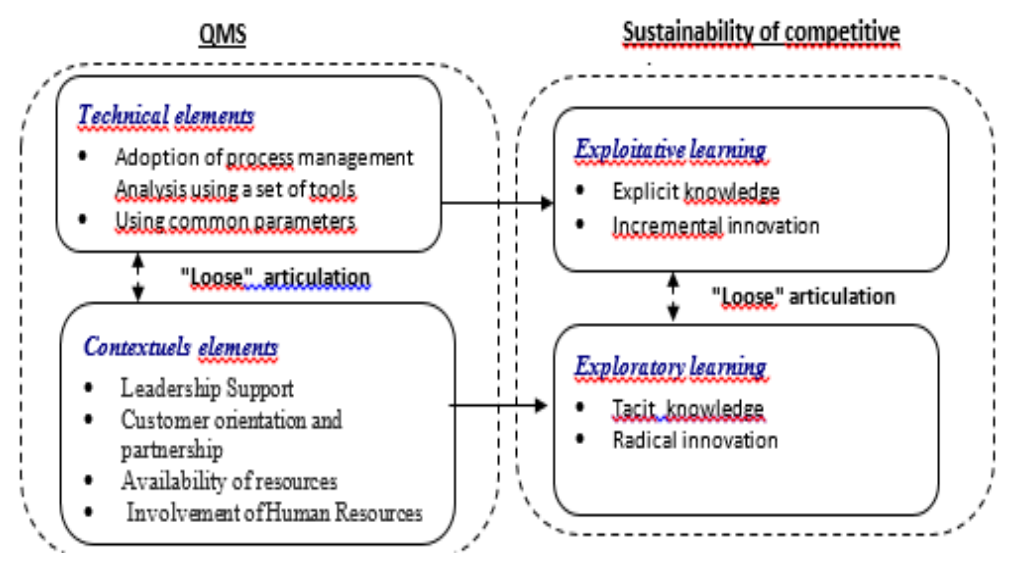

\subsection{The impact of QMS contextual elements on learning, knowledge creation and innovation}

Exploration is: "the search for new ideas, new possibilities that may include variation, risk-taking, gambling, flexibility, discovery, innovation" [3]. It is a learning approach that encourages, in addition to variance, the generation of new ideas and innovative solutions.

For their part, Benner and Tushman [24] combine radical innovations and innovations that meet the needs of new customers under the term "exploration". The organizational context in which people are integrated affects the way learning is created.

Thus, the commitment of leadership in projects improvement, defining ambitious objectives, the deployment of various partnerships, the availability of sufficient resources, the development of staff autonomy, the establishment of a climate of trust, promote exploration and finding new possibilities.

We argue that when the work environment encourages creativity and risk-taking, exploratory learning is likely to be the dominant approach to generate creative ideas and radical innovations. This suggests the following propositions:

P1: Contextual elements generate a higher level of exploratory learning compared to exploitative learning.

P1.1: Contextual elements favor more radical innovation than incremental innovation.

\subsection{The impact of QMS technical elements on learning, knowledge creation and innovation}

March points out that learning can also occur from exploitation which means 'refinement, routinization, production, and implementation of knowledge" [3]. The exploitation relies on a stable organization that guarantees the recurring realization of operations.

While introducing quality systems can, as we have shown, create a favorable environment to exploration, most scholars have considered that quality is oriented towards "more exploitation than exploration" by focusing on the variance reduction, "Although quality can be exploratory as previously argued, most scholars view quality as mostly exploitative focusing on variance reduction" [24].

Quality methods and techniques are more effective in exploiting existing skills and incremental innovation, but they are less effective and can sometimes hinder radical exploration and innovation [24]. This suggests the following propositions:

P2: The technical elements generate a higher level of exploitation learning compared to exploratory learning.

P2.1: The technical elements favor incremental innovation more than radical innovation.

The creation of new explicit knowledge can emerge from the process of converting tacit knowledge into explicit knowledge: process of externalization $[5,16]$.

The QMS Technical Elements generate knowledge that is explicit in nature. For example, adopting the process approach involves: defining a process mapping key of the organization and coding the knowledge that 
is associated with the different processes as procedures. This codification triggers a process of conversion of tacit knowledge into explicit knowledge (process of externalization) and generates explicit knowledge. These can also be generated by the externalization of tacit knowledge in quality circles and the combination of explicit knowledge [5], thanks to the documentation of customer knowledge ". In addition, the use of tools and measuring instruments makes it possible to objectify knowledge and make it explicit. Hence our proposal:

P2.2: Technical elements favor more the creation of explicit knowledge than the creation of tacit knowledge.

Tacit knowledge is personal, specific to the context and because of this, it is difficult to formalize and communicate it. It is knowledge that is acquired mainly through observation and experience [25]. Tacit knowledge can emerge from the internalization of explicit knowledge and the socialization of tacit knowledge [5].

Several authors suggest that quality management and continuous improvement produce not only explicit knowledge, but also tacit knowledge [25]. Quality approaches can contribute to the development of tacit knowledge by creating "enabling context" of contextual elements that encourage creativity and the possibility of innovative action that is of tacit nature. This suggests that the contextual elements of quality favor the creation of tacit knowledge. Hence our proposal:

\section{P1.3: Contextual elements favor more the creation of tacit knowledge than the creation of explicit knowledge. \\ P1.4: Knowledge diversity and innovation, balance between exploitation and exploration for sustainability of competitive advantage.}

In the previous section, we have argued that the technical elements of a quality system favor the development of explicit knowledge while the contextual elements favor the creation of tacit knowledge.

A quality system can serve as a tool for knowledge creation through its contribution to the processes of socialization, outsourcing, combination and internalization. These four types of knowledge conversions alternate and generate a spiral of knowledge creation that transforms the knowledge of the individual at the level of the group and the organization [16].

Several authors suggest that a diversified knowledge base is more advantageous than a homogeneous one: when tacit knowledge is predominant in an organization it runs a risk of dependence on the key skills of its members.

Similarly, where explicit knowledge is predominant, the organization runs the risk of lack of improvement because knowledge is not internalized in processes. On the other hand, according to resource theory, tacit knowledge produces a more lasting advantage because it is difficult to imitate. Because contextual elements facilitate the creation of tacit knowledge and contextual elements facilitate the generation of explicit knowledge, a "looser" rather than narrow articulation between contextual and technical elements is likely to produce heterogeneous knowledge and support the sustainability of the competitive advantage.

P3: a "loose" rather than narrow articulation between contextual and technical elements is likely to produce knowledge diversity.

The sustainability of the competitive advantage can also be explained by the ease of managing the tension between exploitation and exploration at different levels of analysis: at the level of learning, March emphasizes on the need to balance resources that are devoted to each type of learning and ensure their alternation over time. As we have already pointed out, contextual elements of the QMS favor exploratory learning, radical innovation intended for the markets of tomorrow and technical elements favor exploitative learning, incremental innovation, intended for current customers. This suggests that a "loose" articulation between these two sets of elements facilitates the balancing between exploitative learning and exploratory learning and develops a dual innovation capability that facilitates the maintenance and development of the competitive advantage. Hence our proposals: 
P.4: a "loose" rather than narrow articulation between contextual and methodological elements is likely to facilitate the balancing between exploitative learning and exploratory learning, and to develop a dual innovation capability.

P.5: a "loose" rather than narrow articulation between the results of the contextual and methodological elements is likely to maintain and develop the competitive advantage.

\section{Conclusion}

This paper focuses on ISO 9001 quality management and conceptualizes it as a complete system with contextual and methodological elements. By studying these two sets of elements separately, we develop propositions to explain how different types of learning and knowledge can occur. Then, taking into account the contextual and methodological elements together, we argue that the loose coupling between these two groups of elements facilitates the development of a heterogeneous knowledge base and the maintenance of a balance between exploitative learning and that of exploration. We then propose that the heterogeneity of knowledge and the ability to maintain a balance between exploratory and exploitative learning is the basis for the sustainability of the competitive advantage. Knowledge based company approach states that knowledge is the company's most strategic resource that builds its competitive advantage [27]. Our work fits in this vein of research and suggests that types of knowledge (explicit and tacit) and learning processes (learning to explore and exploit) represent key aspects of the sustainability of the quality advantage.

Previous researches have questioned the sustainability of quality programs following application failures [13]. Our study expands this line of research with a focus on the sustainability of the quality advantage and asserts that it is tied to the company's ability to defend its advantage and create new ones. The double effect of a quality management system on learning and knowledge management implies that the implementation of a quality approach would probably be more effective if it is implemented in an organization with ambidextrous structure. Such a structure provides support for relatively diverse and even opposite concurrent activities in an organization. This is consistent with previous work on innovation and learning in terms of maintaining the balance of exploration and the exploitation and managing this tension using an ambidextrous organizational structure [24].

To sum up, our research can help improve our understanding of the links between quality management, learning and knowledge management, and the sustainability of competitive advantage. However, our results remain purely theoretical. Thus, as an extension of our research, we will conduct a quantitative study to test our hypotheses, consolidate and enrich our conceptual framework.

\section{References}

[1] M.Grant Robert, "The Resource-Based Theory of Competitive Advantage: Implications for Strategy Formulation", California Management Review, pp.114-135,1991.

[2] D.J. Teece, " Strategies for Managing Knowledge Assets: the Role of Firm Structure and Industrial Context, Long Range Planning, pp. 35-54, 2000.

[3] J. G., March, «Exploration and Exploitation in Organizational Learning », Organization Science, pp. 71 87, 1991.

[4] R. Garud, A.Kumaraswamy, V. Sambamurthy, "Emergent by Design: Performance and Transformation at Infosys Technologies", Organization Science, pp : 277-286, 2006.

[5] I. Nonaka, "A dynamic theory of organizational knowledge creation", Organization Science 5, 1994, pp. 14-37.

[6] M. Polanyi, the Tacit Dimension, Anchor Day, New York, 1966.

[7] G. Lambert and N. Ouédraogo, « Empirical Investigation of ISO 9000 Quality Management Systems' Impact on Organizational Learning and Process Performances », Total Quality Management and Business Excellence, 2008.

[8] G. Lambert and N. Ouédraogo, « Normes, routines organisationnelles et apprentissage d'entreprise», Revue Française de Gestion, 2010.

[9] F. Mispelblom, "Au-delà de la qualité : démarches qualité, conditions de travail et politiques du bonheur, Paris : Syros, 1995. 
[10] M.J. Zbaracki, « The rhetoric and reality of total quality management », Administrative Science Quarterly, 1998.

[11] N.Ouédraogo, Impact du management de la qualité sur l'apprentissage organisationnel et la gestion des connaissances, Thèse de doctorat ès Sciences de Gestion, Université Robert Schuman, Strasbourg III, 2007.

[12] O. Boiral, «ISO 9000 : Outside the Iron Cage », Organization Science, 2003, pp: 720-737.

[13] J. Igalens, I. Dhaoudi, A. EL Akerimi, "Une analyse critique du Management par la qualité totale : implications pour la GRH ", Revue de gestion des ressources humaines, 2008.

[14] C.C. Manz, G.L Stewart, "Attaining flexible stability by integrating total quality management and sociotechnical systems theory". Organization Science, 1997.

[15] J. G. March and H. A. Simon Organizations, John Wiley and Sons, New York, 1958.

[16] I. Nonaka and H. Takeuchi, "The Knowledge-Creating Company: How Japanese Companies Create the Dynamics of Innovation", Oxford University Press, New York, 1995.

[17] ISO 9001 (2015), « Systèmes de management de la qualité - Exigences ».

[18] R.S. Kaplan, Norton, D.P, "Putting the balanced scorecard to work. Harvard Business Review", 1993.

[19] G., Von Krogh, K. Ichijo, I. Nonaka, "Enabling Knowledge Creation: How to Unlock the Mystery of Tacit Knowledge and Release the Power of Innovation", Oxford University Press, New York, 2000.

[20] P.Senge, "It's the learning: the real lesson of the quality movement", Journal for Quality and Participation, 1999.

[21] W.M. Cohen, D.A. Levinthal, "Absorptive capacity: a new perspective on learning and innovation. Administrative Science Quarterly", 1990.

[22] S.Ghoshal, Bartlett, C.A., "Linking organizational context and managerial action: the dimensions of quality management", Strategic Management Journal, 1994.

[23] E.L. Deci, R.M. Ryan, "Self-Determination Theory and the Facilitation of Intrinsic Motivation, Social Development, and Well-Being", American Psychologist, 2000.

[24] M.J.Benner, M.L Tushman, "Exploitation, exploration, and process management: the productivity dilemma revisited. Academy of Management Review", pp: 238-256, 2003.

[25] I.Daugule and A. Kapenieks, " Knowledge flow analysis: the quantitative method for knowledge stickiness analysis in online course," Periodicals of Engineering and Natural Sciences, vol. 7, pp.165$171,2019$.

[26] M.Osterloh, B.S. Frey, "Motivation, knowledge transfer, and organizational forms". Organization Science, 2000.

[27] B. Kogut and U. Zander, "Knowledge of the Firm, Combinative Capabilities, and the Replication of Technology", Organization Science, 1992. 